\title{
WIND DIRECTION AMBIGUITY REMOVAL BY USING RADARSAT-2 POLARIMETRIC SAR IMAGES
}

\author{
Tahiana Ratsimbazafy, Monique Bernier \\ Institut National de la Recherche Scientifique \\ Centre Eau Terre Environnement
}

\begin{abstract}
A new approach for the wind directions ambiguity removal is proposed. An ambiguity ( $180^{\circ}$ ambiguity) remains on wind directions extracted from Synthetic Aperture Radar (SAR) images. Algorithms based on the detection of geometrical forms in ocean surface are currently used to extract the wind directions from SAR images. The approach proposed in this study is based on signal phase difference through the sea surface. The results show wind directions located at a distance less than $2 \mathrm{~km}$ are subjected to the wave breaking effects and do not have the same threshold (reference phase) as those located offshore $(>10 \mathrm{~km})$. Furthermore, a reference phase based on inter-channel phase combination allows an automatic removal of the ambiguity.
\end{abstract}

Index Terms - Synthetic Aperture Radar, Radar polarimetry, Image processing.

\section{INTRODUCTION}

The ocean surface is the most in contact with the atmosphere boundary layer (BL). Physical phenomena in the BL can leave signatures like linear streaks, eddies on the sea surface. Wind directions are known to be approximately in line with these streaks created by atmospheric roll vortices in the BL [1]. Synthetic Aperture Radar (SAR) installed onboard satellite can be used to image sea surface geometrical features [2-4]. The Fast Fourier Transform algorithm [5-7], wavelet [8,9], and the Local Gradient [3] are currently used to extract wind direction from SAR images. They are based on the detection of geometrical structures. However, an ambiguity $\left(180^{\circ}\right.$ ambiguity) remains on the extracted wind directions. Ancillary data (meteorological mast; scatterometers; buoys) are used to remove the direction ambiguity $[10,11]$. Occasionally, wind wake effect $[12,13]$ located alongside an island can also be used to find the right orientation of the wind directions. A method using polarimetric parameters was also developed for the ambiguity removal [14] on wind direction extracted from polarimetric SAR images.

Particular interest is accorded to coastal zones for wind park installations. At offshore $(\sim 20 \mathrm{~km}))$, Satellite images can be used to produce wind field maps covering large areas at spatial resolution down to $400 \mathrm{~m}$ for the wind speed and $3.2 \mathrm{~km}$ for the wind direction [4].

The objective of this study is to develop a new approach to remove the $180^{\circ}$ ambiguity in wind direction retrieved from wind streaks in SAR images in coastal areas (down to $\sim 1 \mathrm{~km}$ from the shore line).

\section{METHODOLOGY}

The study area is the North-Cape (Figure 1) coastal zone at Prince-Edward-Island, Canada. For the purpose of this study, a total number of eighteen RADARSAT-2 SQ images were acquired in October 2012 and November 2012 via the SOAR-Education program of the Canadian Space Agency (CSA).

All the images were acquired at fall period to avoid ice presence in sea surface near the coast and allow the possibility to analyze the Bragg-scale waves. Wind speeds and directions recorded at the North Cap meteorological mast (Figure 1) are used to validate results. These data record are available at Environment Canada (EC) web site.

The wind directions were extracted by applying the Local Gradient algorithm described in [3]. The spatial resolution of the wind directions produced in this study is $2.4 \mathrm{~km}$. The extracted wind directions still have the $180^{\circ}$ ambiguity. It will be removed with the approach described in the paragraph below.

The approach proposed in this study is based on the use of the phase images inside Single Look Complex (SLC) data of RADARSAT-2 acquired in Standard Quad-polarization (SQ) configuration. The amplitudes and phases of the backscattered signals are recorded in each polarimetric channel. The recorded phases are the phase differences between incident and backscattered signals. Two other parameters are considered in this approach to remove the $180^{\circ}$ ambiguity: reference phase (to determine), the orbital orientation of the satellite during the image acquisition, and the look orientation of the SAR antenna. Equation (1) and (2) show the conditions to be used in the approach.

During the image preprocessing, the phase images are extracted. The spatial resolution was degraded from $25 \mathrm{~m}$ to $400 \mathrm{~m}$. Wind directions were calculated using the Local Gradient Algorithm [3] applied on amplitude image from co-polarized (HH or VV) channel. 
Ascending orbit

$$
\left\{\begin{array}{l}
\varphi_{1}-\varphi_{2}<\varphi_{\text {ref }}=>\operatorname{Dir}(\text { vent })<180^{\circ} \\
\varphi_{1}-\varphi_{2}>\varphi_{\text {ref }}=>\operatorname{Dir}(\text { vent })>180^{\circ}
\end{array}\right.
$$

\section{Descending orbit}

$$
\left\{\begin{array}{l}
\varphi_{1}-\varphi_{2}<\varphi_{\text {ref }}=>\operatorname{Dir}(\text { vent })>180^{\circ} \\
\varphi_{1}-\varphi_{2}>\varphi_{\text {ref }}=>\operatorname{Dir}(\text { vent })<180^{\circ}
\end{array}\right.
$$

These equations were built by considering the phase difference that would be caused by the motions of the Bragg-scale waves. These waves are created by the local wind flow at $10 \mathrm{~m}$ above sea surface level (ASL).

The value of $\varphi_{\text {ref }}$ has been determined by two different methods: The first method consist of finding $\varphi_{\text {ref }}$ value by analyzing a scene with a known wind orientation (testified by the presence of wind shadowing near the coast and meteorological mast data). The value of $\varphi_{\text {ref }}$ is incremented with a pad of $0.5^{\circ}$ from $-25^{\circ}$ to $25^{\circ}$. Each $\varphi_{\text {ref }}$ value is then tested to remove the ambiguity. The number of the corrected directions is used to calculate a score formed by the ratio of the number of the corrected directions and the total number of the calculated wind directions. The second method is finding $\varphi_{\text {ref }}$ by using combination of inter-channel phase. The second method is introduced to allow an automatic processing option for large dataset. The negative of the sum of the absolute value of two phases from different channel were used in $\varphi_{\text {ref }}$ to be used in the ambiguity removal process. These two methods were tested to sense the orientation of wind flow 10m ASL.

$$
\text { score }_{i j}=\frac{\boldsymbol{n}_{i j}}{\boldsymbol{N}}
$$

$\mathbf{n}_{\mathrm{ij}}$ : number of corrected

$\mathbf{N}$ : total number of direction calculated.

The scene of 4 November 2012 at 06:05 p.m (scene A) has wind shadow signature along the east shore and was used to find the best value for $\varphi_{\text {ref }}$ according to the first method.

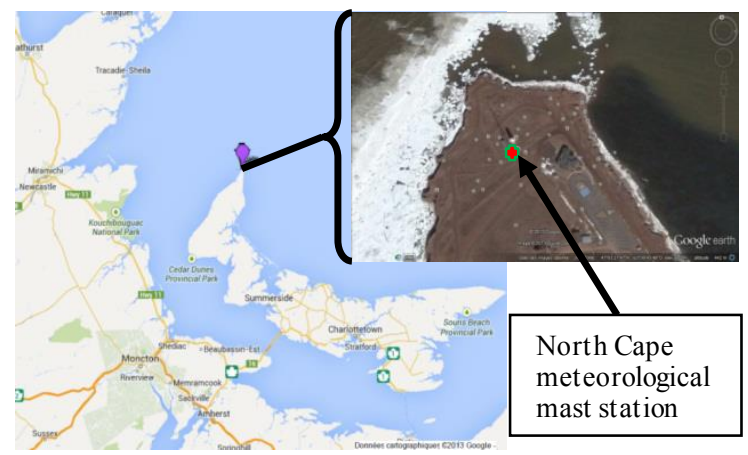

Figure 1: North Cape met mast geographical position (Lat: 47.06 ${ }^{\circ}$; Lon: $\left.-64.00^{\circ}\right)$. Source: Google maps and Google Earth ${ }^{\mathrm{TM}}$

\section{RESULTS AND DISCUSSIONS}

Results from the "method 1" are presented in Figure 2. It represents the score obtained for the phase images in each channel. Based on the graph, a reference phase $\varphi_{\text {ref }}=-20^{\circ}$ was tested with the phase image in the $\mathrm{HH}$ channel from the "scene A". Results show all directions were corrected from the $180^{\circ}$ ambiguity. As the value of $\varphi_{\text {ref }}$ decrease in the negative side of the axis, the better is the result (Figure 3).

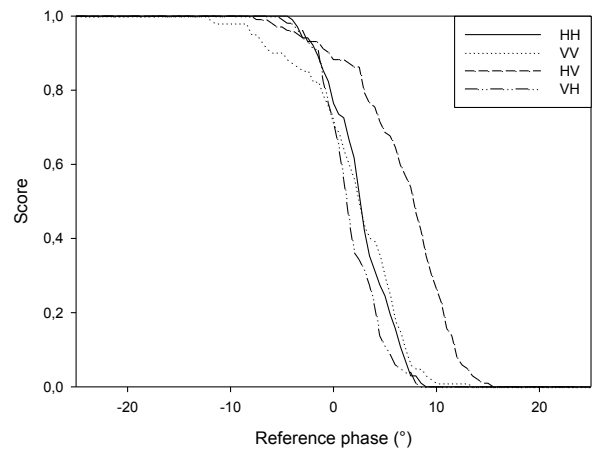

Figure 2: Test results in the channels HH, VV, HV and VH. Wind direction resolution was $2.4 \mathrm{Km}$. The score is the ratio between the number of directions corrected and all in the image.

By using reference phase which is a combination of phase from other channels, the selection of a reference phase value using the graph showed (Figure 2) is no longer needed. In contrast to the first method, the value of the reference phase used is not the same for each pixel in the image. This considers the spatial variation of the signal phase difference through the sea surface with respect to the local wind orientation.

The Figure 3 shows the sensibility of the ambiguity removal in the score value transitions near the reference phase $\varphi_{\mathrm{ref}}=0^{\circ}$. Through the Figure 3a, 3b, 3c, and 3d, all new corrected directions are indicated with red circles. Wind directions closest to the shore are corrected lately when the reference phase $\left(\varphi_{\text {ref }}\right)$ is changed from $0^{\circ}$ to $-3^{\circ}$. This could be due to the wave breaking effect on the Bragg-scale wave motion. The orientation of this motion may be changed by the energy propagation from wave breaking at the coast.

The results from the second method are presented in Table I. Most of them give the maximum score (1 or $100 \%$ ). This could be the effect of taking the minus of an absolute value of the phase combination used in the method. This choice leads to have results comparable to the left region in the graphic shown in Figure 2. 

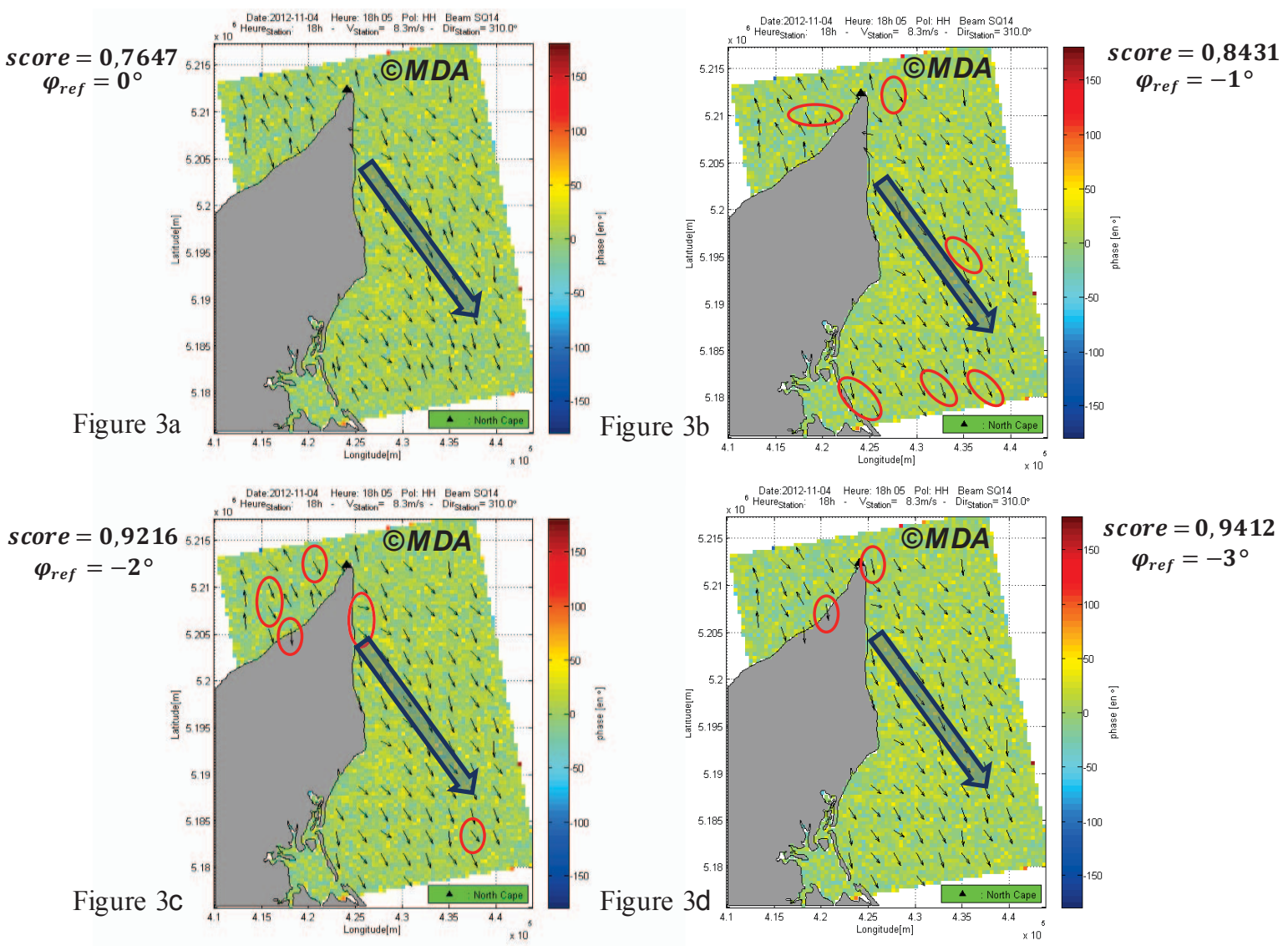

Figure 3: Phase values in $\mathrm{HH}$ polarization and wind directions (small arrows). Different reference phase values were used: Fig.3a) $\varphi_{\text {ref }}=0^{\circ}$, Fig.3b) $\varphi_{\text {ref }}=-1^{\circ}$, Fig.3c) $\varphi_{\text {ref }}=-2^{\circ}$, and Fig 3d) $\varphi_{\text {ref }}=-3^{\circ}$. The color bar shows phase values in the images. The spatial resolution is $2.4 \mathrm{~km}$ for the wind directions and $400 \mathrm{~m}$ for the phase image. The bold arrow indicates the real wind orientation in the scene. The red circles indicate newly wind directions freed from $180^{\circ}$ ambiguity.

Table I: Score for each polarization according to "method 2 ". $\mathrm{n}_{\mathrm{ij}}$ is the number of corrected directions and $\mathrm{N}$ is the total number of calculated directions on the image SQ14 of Nov. 04,2012. Index indicate the polarization channel for the phase image used to compare with $\varphi_{\text {ref }}$

\begin{tabular}{ccccc}
\hline$\varphi_{\text {ref }}$ & score $_{H \boldsymbol{H}}$ & score $_{\boldsymbol{W}}$ & score $_{\boldsymbol{H V}}$ & score $_{\boldsymbol{V H}}$ \\
\hline$-\left(\left|\varphi_{\mathrm{HH}}\right|+\left|\varphi_{\mathrm{VV}}\right|\right)$ & 1 & 1 & 1 & 0,96 \\
$-\left(\left|\varphi_{\mathrm{HH}}\right|+\left|\varphi_{\mathrm{HV}}\right|\right)$ & 1 & 0,88 & 1 & 0,98 \\
$-\left(\left|\varphi_{\mathrm{HH}}\right|+\left|\varphi_{\mathrm{VH}}\right|\right)$ & 1 & 0,87 & 0,97 & 1 \\
$-\left(\left|\varphi_{\mathrm{VV}}\right|+\left|\varphi_{\mathrm{HV}}\right|\right)$ & 1 & 1 & 1 & 1 \\
$-\left(\left|\varphi_{\mathrm{VV}}\right|+\left|\varphi_{\mathrm{VH}}\right|\right)$ & 0,99 & 1 & 1 & 1 \\
$-\left(\left|\varphi_{\mathrm{HV}}\right|+\left|\varphi_{\mathrm{VH}}\right|\right)$ & 1 & 0,89 & 1 & 1 \\
\hline
\end{tabular}




\section{CONCLUS ION}

A new approach to remove the $180^{\circ}$ ambiguity in wind directions extracted from RADARSAT-2 Standard Quadpolarization scenes was presented. It is based on the comparison of a reference phase value to the phase differences recorded inside the polarimetric images. Two approaches were presented, both give satisfactory results.

In the second method, the reference phase values needed for the ambiguity removal varies in space. The wind directions have not the same sensibility to the removal criteria. The use of a combination of phase values from different channels is more suitable for removing the ambiguity.

An inter-channel polarimetric phase difference should give better results and will be tested. The presented approaches could be useful for wind field extraction from the future compact polarization data of RADARSATConstellation.

\section{ACKNOWLEDGEMENTS}

We are grateful to MacDonald, Dettwiler and Associates Ltd and the Canadian Space Agency for all the RADARSAT-2 scenes provided through the SOAREducation Program.

\section{REFERENCES}

[1] J. Horstmann, W. Koch, S. Lehner, and R. Tonboe, "Ocean winds from RADARSAT-1 ScanSAR," Canadian Journal of Remote Sensing, vol. 28, pp. 524533, June 20022002.

[2] J. Horstmann and W. Koch, "Measurement of Ocean Surface Winds Using Synthetic Aperture Radars," IEEE JOURNAL OF OCEANIC ENGINEERING, vol. 30, 2005.

[3] W. Koch, "Directional analysis of SAR images aiming at wind direction," IEEE Transactions on Geoscience and Remote Sensing, vol. 42, pp. 702-710, Apr 2004.

[4] T. Bergeron, M. Bernier, K. Chokmani, A. LessardFontaine, G. Lafrance, and P. Beaucage, "Wind Speed Estimation Using Polarimetric RADARSAT-2 Images: Finding the Best Polarization and Polarization Ratio," IEEE Journal of Selected Topics in Applied Earth Observations and Remote Sensing, vol. 4, pp. 896-904, 2011.

[5] B. R. Furevik and H. A. Espedal, "Wind energy mapping using synthetic aperture radar," Canadian Journal of Remote Sensing, vol. 28, pp. 196-204, Apr 2002.

[6] M. B. Christiansen, W. Koch, J. Horstmann, C. B. Hasager, and M. Nielsen, "Wind resource assessment from C-band SAR," Remote Sensing of Environment, vol. 105, pp. 68-81, Nov 2006.
[7] T. W. Gerling, "Structure of the surface wind field from the Seasat SAR," Journal of Geophysical Research, vol. 91, p. 2308, 1986.

[8] Y. Du, P. W. Vachon, and J. Wolfe, "Wind direction estimation from SAR images of the ocean using wavelet analysis," Canadian Journal of Remote Sensing, vol. 28, pp. 498-509, 2002.

[9] N. Fichaux and T. Ranchin, "Evaluating offshore wind energy resource by spaceborne radar sensors: The use of advanced signal processing techniques," Toulouse, 2002, pp. 135-144.

[10] F. Fetterer, D. Gineris, and C. C. Wackerman, "Validating a scatterometer wind algorithm for ERS-1 SAR," Geoscience and Remote Sensing, IEEE Transactions on, vol. 36, pp. 479-492, 1998.

[11] W. Koch and F. Feser, "Relationship between SARDerived Wind Vectors and Wind at 10-m Height Represented by a Mesoscale Model," 2006.

[12] Horstmann J., Lehner S., Koch W., and T. R., "Computation of wind vectors over the ocean using spaceborne Synthetic Aperture Radar," Johns Hopkins Apl Technical Digest, vol. 21, 2000.

[13] S. Lehner, J. Horstmann, W. Koch, and W. Rosenthal, "Mesoscale wind measurements using recalibrated ERS SAR images," Journal of Geophysical Research: Oceans (1978-2012), vol. 103, pp. 7847-7856, 1998.

[14] B. Zhang, W. Perrie, P. W. Vachon, L. Xiaofeng, W. G. Pichel, G. Jie, et al., "Ocean Vector Winds Retrieval From C-Band Fully Polarimetric SAR Measurements," Geoscience and Remote Sensing, IEEE Transactions on, vol. 50, pp. 4252-4261, 2012. 